PERSPECTIVES ON VALUE 115

\title{
The ICER review is in: hope amidst uncertainty
}

\author{
Wendy Smith Begolka, MBS; Lisa Butler, MBA; and Michele Guadalupe, MPH
}

Atopic dermatitis (AD) is one of the most common chronic inflammatory skin diseases in the United States. Although most often disease begins in childhood, increasingly initial diagnosis is made well into adulthood, affecting at least $13 \%$ of children and $7 \%$ of adults. ${ }^{1-3}$ Research is proving $\mathrm{AD}$ to be a heterogeneous disease with variable severity and disease course over time. It also presents burdensome symptoms, including substantial itch, skin pain, sleep disruption, and mental health issues such as anxiety and depression. ${ }^{2,4-6}$ It is associated with reduced health-related quality of life for patients as well as caregivers, resulting in impaired physical, emotional, and psychosocial well-being. The multifaceted burden of $\mathrm{AD}$ is also associated with considerable direct and indirect costs to society, including an inflation-adjusted estimated annual cost of $\$ 5.3$ billion in 2015. ${ }^{8}$

Despite this significant personal, familial, and societal burden, until recently, treatments for $\mathrm{AD}$ have been limited and have had variable longterm efficacy, especially for those with moderate to severe AD. Excitingly, new treatment options are emerging to better control $\mathrm{AD}$ and improve quality of life, as well as better alleviate itch-the most problematic symptom reported by patients. ${ }^{5}$ Dupilumab, the first approved biologic for the treatment of $\mathrm{AD}$ (now approved for patients aged 6 years and up), as well as other biologics and small molecule therapies, such as the Janus kinase (JAK) inhibitors, have the potential to dramatically change and improve the management of AD. ${ }^{9,10}$ They also have the potential to afford patients long sought-after options in treatment-to accommodate patient preferences that can affect treatment adherence, the inherent disease heterogeneity of $\mathrm{AD}$ over a course of a lifetime, and treatments that are not equally effective for all. The treatment toolbox needs more, and different, tools.

The National Eczema Association (NEA) served as a key stakeholder representing the patient/patient advocacy community at the recent Institute for Clinical and Economic Review (ICER) assessment of JAK inhibitors and monoclonal antibodies for the treatment of AD. The final ICER report acknowledged the significant burden $\mathrm{AD}$ places on "all aspects of patients' lives and those of their family and caregivers," with all assessed therapies receiving a favorable vote on the net health benefit when compared with usual care alone. ${ }^{11}$ We appreciated that ICER recognized these burdens and that we had the opportunity to highlight crucial points of the lived experience for those with $\mathrm{AD}$ and their caregivers that underscores the need for additional treatment options.

Now that the ICER report is complete, the $\mathrm{AD}$ patient and caregiver community waits with hope, but also with tremendous uncertainty.

\author{
Author affiliations \\ Wendy Smith Begolka, MBS; Lisa Butler, \\ MBA; and Michele Guadalupe, MPH, \\ National Eczema Association, Novato, CA. \\ AUTHOR CORRESPONDENCE: \\ Wendy Smith Begolka, \\ wendy@nationaleczema.org \\ J Manag Care Spec Pharm. \\ 2022;28(1):115-18 \\ Copyright $\odot 2022$, Academy of Managed \\ Care Pharmacy. All rights reserved.
}

We wait for the final decision of the US Food and Drug Administration regarding oral JAK inhibitors and tralokinumab for AD. We wait to better understand how health care providers will pull these new treatments from the toolbox given available data, and who will be offered these new options. And, we wait to see how policymakers and payers will interpret the "promising but inconclusive" ICER rating for these new drugs: how easy or difficult they will be to obtain and how much these new therapies will cost out of pocket (OOP).

This uncertainty sits on top of a current understanding of the OOP costs associated with AD management. A new study published by NEA revealed that $42 \%$ of Americans living with AD spend $\$ 1,000$ or more out of 


\section{FIGURE 1 US Patient-Reported Annual OOP Expense for AD}

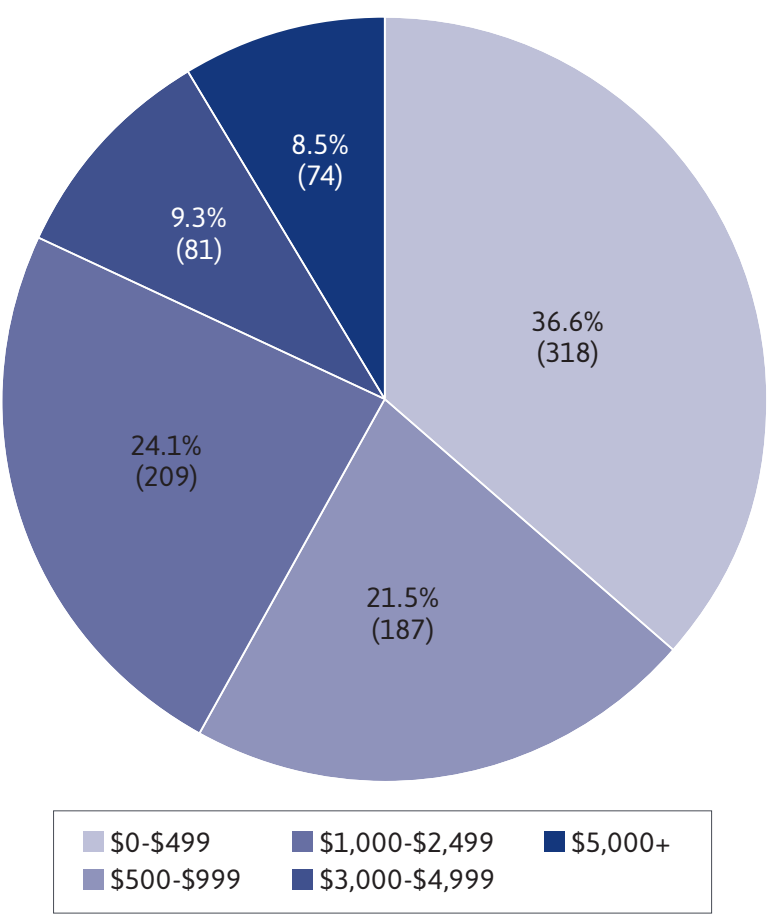

Source: Smith Begolka W, Chovatiya R, Thibau I, Silverberg JI. Financial burden of atopic dermatitis out-of-pocket health care. ${ }^{12}$ Reprinted with permission. $A D=$ atopic dermatitis; $O O P=$ out of pocket.

pocket every year to care for and manage their eczema (Figure 1); 8.5\% reported OOP costs greater than $\$ 5,000$ per year, with higher OOP costs associated with increasing disease severity, increased disease flares, and poorer disease control. ${ }^{12}$ Nearly half of all study respondents (48.6\%) reported OOP costs for prescription medications that were not covered by insurance. Black respondents with AD were also significantly more likely to report OOP costs for prescription medications both covered and not covered by insurance, resulting in increased overall household financial impact from OOP costs. ${ }^{13}$ Overall, nearly a quarter of $A D$ patients reported a significant or devastating impact of OOP expenses on their household finances (Figure 2). ${ }^{14}$

Not only do AD treatment-related expenses result in personal spend prioritization and opportunity costs, but when cost becomes a barrier to access, patients may not use their medications appropriately, skipping doses to save money or abandoning treatment altogether. Prescription abandonment rates in other disease areas increase significantly

\section{FIGURE 2 Patient-Reported Impact of OOP Health Care Expenses for AD on Household Finances}

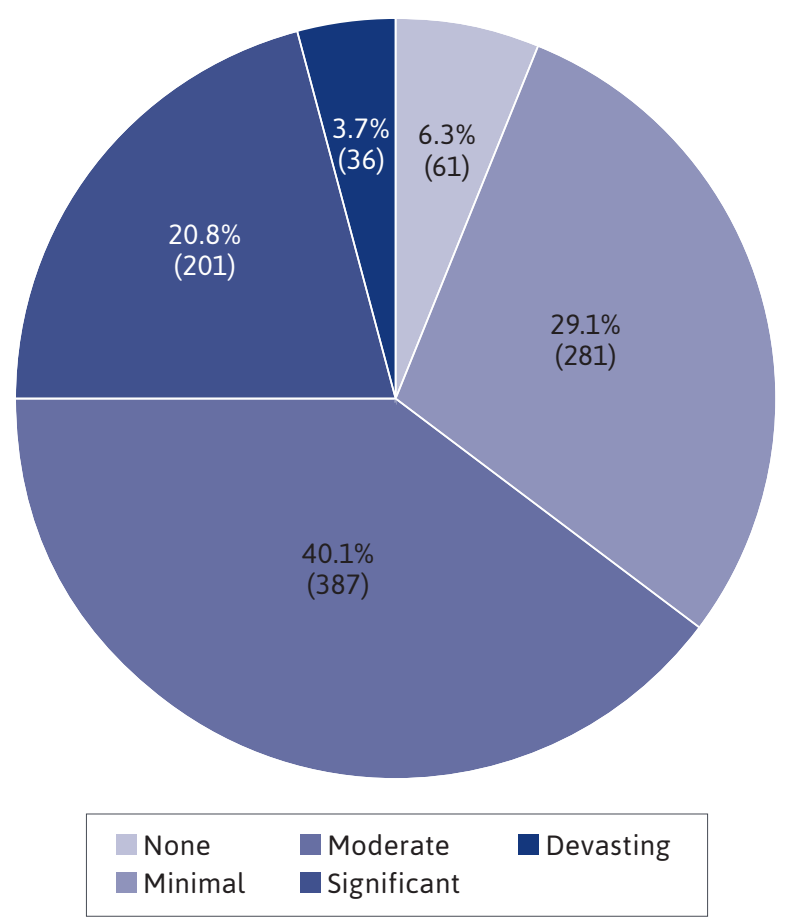

Source: Chovatiya R, Begolka WS, Thibau IJ, Silverberg JI. Impact and associations of atopic dermatitis out-of-pocket health care expenses in the United States. ${ }^{14}$ Reprinted with permission.

$A D=$ atopic dermatitis; $O O P=$ out of pocket.

when cost sharing exceeds $\$ 100{ }^{15}$ but it is unknown how this translates to AD.

New AD therapies, while acutely needed, may result in higher deductible payments, which can result in higher OOP costs. The ICER report policy recommendations stated the importance of ensuring that AD patients can cover the cost of therapy and that new therapies intended to improve the health of patients and families do not aggravate existing health inequities. NEA is already taking steps to encourage patients and health care providers to include potential OOP costs as part of the treatment decision-making conversation and recommends that insurance plans provide patients with options that do not include high up-front prescription costs, as well as transparency in cost sharing to facilitate these important discussions.

In addition to OOP expenses, access issues related to utilization management for therapies involved in the treatment of $\mathrm{AD}$ (eg, prior authorization) have been previously 
reported with variable coverage outcomes and time frames for coverage determinations. ${ }^{16-18}$ Preliminary data from a recently conducted NEA survey on access to prescription treatments also found that of respondents taking prescription medication for $\mathrm{AD}$, $50 \%$ experienced at least 1 treatment delay or denial in the past 12 months (unpublished observation).

The recent ICER review also recommended that payers ensure that benefit designs developed in conjunction with employers and other plan sponsors do not create requirements for OOP spending that cause major barriers to appropriate access for vulnerable patients. Requirements such as step therapy, especially if required to re-step through previously failed therapies, can potentially be a significant barrier to necessary treatments for people with AD. The time and administrative burden associated with step therapy presents an obstacle to access that may lead to unnecessary breaks in treatment. Indeed, studies investigating different drug types outside $\mathrm{AD}$ have found that, depending on the therapeutic class, $7 \%-22 \%$ of patients did not submit any class-related prescription claim to their insurers within 12 months after insurer-requested step therapy, instead foregoing prescribed treatment. ${ }^{19,20}$ Future NEA survey analysis may be able to provide an assessment of this for the $\mathrm{AD}$ community.

It is an exciting time for the $\mathrm{AD}$ treatment landscape, with the new JAK inhibitors and biologics representing the newest tools for the toolbox-many dozens more are in development. Yet the paradox of hope amidst uncertainty, with approval, cost, and use decisions being made beyond the patient community, leaves those living with this disease and those who care for them hanging in the balance. While the scale could appear to be tipping away from "right treatment, right patient, right time," the ICER review's conclusion-that the $\mathrm{AD}$ patient community should have access to a wide range of affordable and effective therapies-gives hope.

But for now, we wait.

\section{DISCLOSURES}

No funding contributed to the writing of this commentary. Smith Begolka, Butler, and Guadalupe are salaried employees of the National Eczema Association, which has received grants and sponsorship awards from a variety of industry partners, including AbbVie, Eli Lilly, Incyte, LEO Pharma, Pfizer, Regeneron, and Sanofi. Smith Begolka has received grant funding from Pfizer and advisory board honoraria from Pfizer and Incyte. Butler and Guadalupe have received advisory board honoraria from Incyte.

\section{REFERENCES}

1. Hua T, Silverberg JI. Atopic dermatitis in US adults: epidemiology, association with marital status, and atopy. Ann Allergy Asthma Immunol. 2018;121(5):622-24.

2. Silverberg JI, Simpson EL. Associations of childhood eczema severity: A US population-based study. Dermatitis. 2014;25(3):107-14.

3. Silverberg JI, Gelfand JM, Margolis DJ, et al. Patient burden and quality of life in atopic dermatitis in US adults: a population-based cross-sectional study. Ann Allergy Asthma Immunol. 2018;121(3):340-47.

4. Weidinger S, Beck LA, Bieber T, et al. Atopic dermatitis. Nat Rev Dis Primers. 2018;4(1):1.

5. McCleary KK. Understanding the lived experience of eczema: the "voice of the patient" report on the eczema patientfocused drug development meeting. 2020. Accessed November 17, 2021. http://www. morethanskindeep-eczema.org/report. $\underline{\text { html }}$

6. Kim JP, Chao LX, Simpson EL, et al. Persistence of atopic dermatitis (AD); a systematic review and meta-analysis. J Am Acad Dermatol. 2015;135(1)56-66.
7. Bridgman AC, Block JK, Drucker AM. The multidimensional burden of atopic dermatitis an update. Ann Allergy Asthma Immunol. 2018;120(6):603-06.

8. Drucker AM, Wang AR, Li WQ, et al. The burden of atopic dermatitis: summary of a report for the National Eczema Association. J Invest Dermatol. 2017;137(1):26-30.

9. Renert-Yuval Y, Guttman-Yassky E. What's new in atopic dermatitis. Dermatol Clin. 2019;37(2):205-13.

10. Scott JB, Paller AS. Novel treatments for pediatric atopic dermatitis. Curr Opin Pediatr. 2021;33(4):392-401.

11. Atlas SJ, Brouwer E, Fox G, et al. JAK inhibitors and monoclonal antibodies for the treatment of atopic dermatitis: effectiveness and value. Evidence report. Institute for Clinical and Economic Review. July 9, 2021. Accessed November 17, 2021. https://icer.org/wp-content/ uploads/2020/12/Atopic-Dermatitis Revised-Evidence-Report_070921.pdf

12. Smith Begolka W, Chovatiya R, Thibau I, Silverberg JI. Financial burden of atopic dermatitis out-of-pocket health care expenses in the United States. Dermatitis. 2021;32(1S):S62-S70.

13. Chovatiya R, Begolka WS, Thibau IJ, Silverberg JI. Financial burden and impact of atopic dermatitis out-of-pocket healthcare expenses among black individuals in the United States. Arch Dermatol Res. September 27, 2021. Online ahead of print. doi:10.1007/s00403-021-02282-3

14. Chovatiya R, Begolka WS, Thibau IJ, Silverberg JI. Impact and associations of atopic dermatitis out-of-pocket health care expenses in the United States. Dermatitis. September 27, 2021. Online ahead of print. doi:10.1097/ DER0000000000000795

15. Streeter SB, Schwartzberg LS, Husain N, Johnsrud MT. Patient and plan characteristics affecting abandonment of oral oncolytic prescriptions. Am J Manag Care. 2011;17(S5):SP38-44. 
16. Petitt CE, Kiracofe E, Adamson A, Barbieri JS. Prior authorizations in dermatology and impact on patient care: an updated survey of US dermatology providers and staff by the American Academy of Dermatology. Dermatol Online J. 2021;27(1):5

17. Guo LN, Nambudiri VE. Impact of prior authorizations on dermatology patients: a cross-sectional analysis. J Am Acad Dermatol. 85(1):217-20.
18. Wang CY, Zheng RRC, Doerrer ZA, et al. Health care regulation, the Food and Drug Administration (FDA), and access to medicine: our experience with dupilumab for children. J Am Acad Dermatol. 2020;82(6):1568-69.

19. Delate T, Mager DE, Sheth J, Motheral BR. Clinical and financial outcomes associated with a proton pump inhibitor prior-authorization program in a Medicaid population. Am J Manag Care. 2005;11(1):29-36.
20. Yokoyama K, Yang W, Preblick R, Frech-Tamas F. Effects of a steptherapy program for angiotensin receptor blockers on antihypertensive medication utilization patterns and cost of drug therapy. J Manag Care Pharm. 2007;13(3):235-44. doi:10.18553/ imcp.2007.13.3.235 